\title{
Evaluation of Speech Recognition Skills in Different Noises with the Turkish Matrix Sentence Test in Hearing Aid Users
}

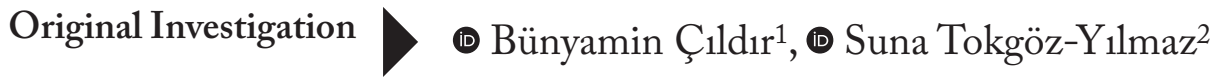 \\ ${ }^{1}$ Department of Language and Speech Therapy, Ankara Yıldırım Beyazıt University Faculty of Health Sciences, Ankara, \\ Turkey \\ ${ }^{2}$ Department of Audiology, Ankara University Faculty of Health Sciences, Ankara, Turkey
}

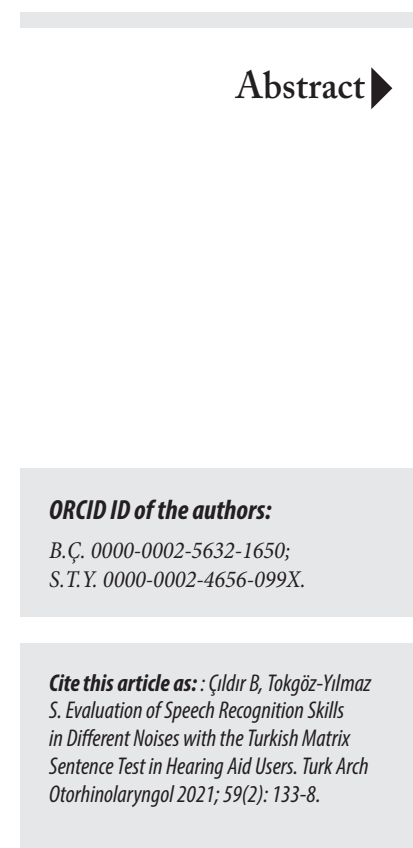

Corresponding Author: Bunyamin Çıldır; bunyamin.cildir@gmail.com

Received Date: 09.12.2020 Accepted Date: 27.02 .2021

Content of this journal is licensed under a Creative Commons Attribution 4.0 International License. Available online at www.turkarchotolaryngol.net
Objective: This study aimed to analyze the effectiveness of the Turkish matrix sentence test in evaluating the speech recognition performance of hearing aid users under different noise conditions.

Methods: Speech recognition performance of 42 individuals, 20 to 65 years of age (mean $49.1 \pm 14$ years) with bilateral sensorineural hearing loss was measured in noise with the Turkish matrix sentence test without a background noise and with headphones. Additionally, the participants' speech recognition thresholds were measured with a matrix test while wearing their hearing aid under three different listening conditions in which the phases of speech and noise stimuli were changed with constant and fluctuating noise.

Results: Speech-recognition thresholds were better in fluctuating noise than in constant noise in all listening conditions, and this difference was statistically significant $(\mathrm{p}=0.02)$. In both types of noise, speech-recognition thresholds of bilateral hearing aid users $(n=29)$ were lower (better) than those of unilateral hearing aid users $(\mathrm{n}=13)$ under three different listening conditions, but there was no statistically significant difference $(\mathrm{p}=0.67)$. Speech-recognition thresholds without hearing aids were statistically higher (worse) than those obtained with hearing aids $(\mathrm{p}=0.001)$.

Conclusion: Since the Turkish matrix sentence test gives useful results, this test can be used in the diagnosis, follow-up, and rehabilitation planning of hearing aid users. We observed that speech intelligibility was better, although there were differences among those with hearing loss when the speech test was conducted in fluctuating background noise with the Turkish matrix sentence test. Keywords: Hearing loss, hearing aid, auditory rehabilitation, Turkish matrix sentence test, fluctuating noise, constant noise, speech audiometry 


\section{Introduction}

One of the most significant problems faced by individuals with hearing disorders is the impairment of speech perception in noise (1). The degree of speech perception may vary depending on the sound in the background, particularly on its temporal and spectral characteristics (2, 3). Hearing problems, including catching clues from speech context, can persist even with hearing amplification devices, particularly in challenging listening conditions, such as noisy and reverberant environments $(4,5)$. Tests involving speech recognition skills in different types of background noise should be applied when assessing the benefits obtained by patients from hearing aids equipped with complex signal processing algorithms $(6,7)$. The literature describes various methods for speech perception testing in different languages and presentation formats (including intermittent or continuous complex noise) (8-10). Assessment results vary according to the language or the procedures used in these tests. This led to the development of diagnostic tests such as the matrix sentence test and the hearing in noise test (HINT), which use different adaptive methods (noisy/noiseless conditions) and are suitable for many languages because they use the same syntactical structure (11-13). These sentence tests provide identical sentence-formation criteria for languages with low linguistic complexity. The vocabulary material used in these tests were selected to include phonetically balanced common words. The tests can be administered in a closed- or open-ended response format and in the native language of each patient $(13,14)$.

Various word lists can be created using different types of background noise (which either fluctuates according to the sentences used or maintains the same frequency distribution) to determine speech recognition scores through a matrix sentence test $(7,15)$. Constant speech noise and fluctuating filtered speech noise methods were developed to achieve adequate measurement accuracy in noise (15). Fluctuating filtered speech noise, which is used to evaluate hearing aid specifications, has been redesigned to evaluate the speech perception performance of individuals who have a hearing disorder and normal hearing sensitivity $(6,8)$.

The goal of the presented study was to analyze the effectiveness of the Turkish matrix sentence test (TMST) in different types of background noise when evaluating the speech recognition performance of hearing aid users.

\section{Materials and Methods}

This study was approved by Ankara Yildirım Beyazıt University Ethics Committee (approval no: 55-14) and conducted according to the Helsinki Declaration. Informed consent forms were signed by all participants.

\section{Participants}

A total of 42 native Turkish speakers with bilateral sensorineural hearing loss and who had been using hearing aids for at least six months were included in this study. All participants were in the age range of 20-65 years (mean $49.1 \pm 14$ years). They were divided into two groups: one with 29 individuals (12 females and 17 males) using bilateral hearing aids and the other with 13 individuals (five females and eight males) using unilateral hearing aids (Table 1). The air conduction hearing thresholds of the participants were tested with Sennheiser TDH $49 \mathrm{P}$ supra-aural headphones using Otometrics Madsen Astera audiometry (Aurical Aud, Otometrics; Taastrup, Denmark) connected to a computer. Speech recognition scores were tested using a Turkish monosyllabic balanced word list, and individuals who scored higher than $70 \%$ were included in the study (16). All audiological tests were conducted in soundproof rooms according to international standards (17). To obtain speech recognition scores with hearing aids during the TMST, Oldenburger software program equipped with free-field speakers, which were calibrated to standards specified by the manufacturer and connected to the Otometrics Madsen Astera audiometry device (Hörtech, Oldenburg, Germany), was used for speech recognition scores with hearing aids.

\section{Stimuli and Procedure}

The TMST developed by Zokoll et al. (14) was used to evaluate the speech skills of participants when wearing a hearing aid in different types of background noise. Each sentence used in the TMST was created using words that are frequently employed in daily life. The test material included 20 randomly selected sentences from a list of 100 sentences and was presented in an electronic environment using the open-ended presentation model. The score was calculated as the percentage of words repeated by the participants. The software changed each subsequent sentence automatically, applying either the adaptive or the non-adaptive method as the number of correctly repeated words in the last sentence increased. The non-adaptive intelligibility scores of the

\begin{tabular}{l|l|l|l|}
\multicolumn{2}{l}{ Table 1. Hearing levels of participants } & \multicolumn{4}{l}{} \\
\hline & Age & Right PTA (dB HL) & Left PTA (dB HL) \\
\hline Unilateral HA & $53.4 \pm 15.2$ & $39.4 \pm 9$ & $35.2 \pm 11$ \\
\hline Bilateral HA & $47.3 \pm 13.2$ & $52.4 \pm 8.1$ & $52.2 \pm 7.9$ \\
\hline
\end{tabular}


TMST participants were determined as the percentage of the correct responses and compared with the speech recognition scores with headphones. The adaptive procedure was preferred in our study because it determines the signalto-noise ratio automatically, and the test was started with a 0 $\mathrm{dB}$ signal-to-noise ratio at a constant $65 \mathrm{~dB}$ sound pressure level (SPL) with hearing aids. The difficulty level of the subsequent sentence was based on a correct understanding of $50 \%$ of the words in the current sentence (18).

In the present study, two different types of artificial noise (constant and fluctuating) were used. The first type of noise has the same frequency distribution as sentences with constant noise (Matrix noise) (8). The other noise is fluctuating, which has similar spectral and temporal characteristics with a speech and used in International Collegium for Rehabilitative Audiology (ICRA) $(6,19)$. To create the ICRA noise, four different speakers read the text followed by filtering with three bands $(800 \mathrm{~Hz}$ low pass, $800-2400 \mathrm{~Hz}$ bandpass, and $2400 \mathrm{~Hz}$ high pass). The resulting signal was filtered with a $100 \mathrm{~Hz}$ high-pass filter to create the final ICRA 5 noise (19).

After adaptive TMST was performed in a quiet environment using Sennheiser HDA200 headphones, TMST was performed with hearing aids using a free field speaker at different azimuths $\left(\mathrm{S}_{0} \mathrm{~N}_{0}, \mathrm{~S}_{0} \mathrm{~N}_{90}\right.$ and $\left.\mathrm{S}_{0} \mathrm{~N}_{270}\right)$. In the first listening situation, speakers were placed in front and on the right side of the individuals, and speech and noise were simultaneously given through the speaker in front of the patient at the angle $\mathrm{S}_{0} \mathrm{~N}_{0}$ (azimuth 0). In the $\mathrm{S}_{0} \mathrm{~N}_{90}$ listening situation, the speech stimulus was presented from the patient's face, while the noise stimulus was presented from the right side of the patient. In the $\mathrm{S}_{0} \mathrm{~N}_{270}$ listening state, after the patient was moved to face the speaker on the right, the speech stimulus was presented from the face of the patient and the noise stimulus was presented from the left side of the patient.

\section{Statistical Analysis}

Data analysis was conducted with IBM SPSS version 23.0 (Statistical Package for Social Sciences) (Armonk, NY: IBM Corp). The Mann-Whitney U test was used to compare two nonparametric variables. The nonparametric Wilcoxon test was used for comparing two dependent groups. The significance level was set as $\mathrm{p}=0.05$.

\section{Results}

The mean right and left ear pure-tone air conduction of the participants was $50.43 \pm 8.6 \mathrm{~dB} \mathrm{HL}$ and $50.15 \pm 8.4 \mathrm{~dB} \mathrm{HL}$, respectively (Table 1 ). The difference between the two ears of the participants was not statistically significant $(\mathrm{p}=0.12)$. The mean TMST non-adaptive speech intelligibility test score of individuals with hearing loss was $88.02 \pm 6.12 \%$ with headphones in quiet (65 dB SPL fixed speech level).

In fluctuating noise, the speech recognition thresholds of bilateral hearing aid users were lower (better) than those of unilateral hearing aid users under $\mathrm{S}_{0} \mathrm{~N}_{0}$ and $\mathrm{S}_{0} \mathrm{~N}_{270}$ listening conditions, but there was no statistically significant difference between the two groups $(p=0.67)$. In constant noise, the speech recognition thresholds were found to be better only under $\mathrm{S}_{0} \mathrm{~N}_{90}$ listening conditions for bilateral hearing aid users but not unilateral hearing aid users $(\mathrm{p}=0.023)$ (Figure 1). Bilateral hearing aid users showed a significant difference between their adaptive TMST scores obtained with and without hearing aids in constant noise under $\mathrm{S}_{0} \mathrm{~N}_{90}(\mathrm{p}=0.001)$ and $\mathrm{S}_{0} \mathrm{~N}_{270}(\mathrm{p}=0.001)$ listening conditions. In fluctuating noise, a statistical difference was observed between the results obtained under $\mathrm{S}_{0} \mathrm{~N}_{0}(\mathrm{p}=0.007)$ and $\mathrm{S}_{0} \mathrm{~N}_{270}(\mathrm{p}=0.001)$ conditions.

The speech recognition thresholds of all participants were determined with and without hearing aids, and the scores obtained under fluctuating noise conditions were significantly lower than those obtained under constant noise conditions $(\mathrm{p}=0.02)($ Table 2$)$.

Table 2. Turkish matrix sentences test findings of individuals with/without hearing aid

TMST value without HA

\begin{tabular}{|l|l|l|l|l|l|l|l|l|}
\hline $\begin{array}{l}\text { Listening } \\
\text { conditions }\end{array}$ & Noise type & Min & Max & Mean $\pm \mathrm{SD}$ & Min & Max & Mean \pm SD \\
\hline $\mathrm{S}_{0} \mathrm{~N}_{0}$ & Constant & -5.80 & 10.70 & $-0.32 \pm 3.72$ & -5.90 & 5.10 & $-1.84 \pm 3.05$ \\
\hline $\mathrm{S}_{0} \mathrm{~N}_{90}$ & -9.20 & 6.60 & $-0.70 \pm 4.37$ & -10.90 & 4.00 & $-4.04 \pm 3.54$ & $0.012^{*}$ \\
\hline $\mathrm{S}_{0} \mathrm{~N}_{270}$ & & -13.30 & 6.20 & $-2.57 \pm 4.97$ & -15.00 & 6.00 & $-6.81 \pm 4.08$ \\
\hline $\mathrm{S}_{0} \mathrm{~N}_{0}$ & & -10.00 & 10.90 & $-1.80 \pm 4.98$ & -11.10 & 8.20 & $-4.21 \pm 4.54$ & $0.001^{*}$ \\
\hline $\mathrm{S}_{0} \mathrm{~N}_{90}$ & Fluctuating & -10.30 & 6.20 & $-2.63 \pm 3.79$ & -12.10 & 8.40 & $-2.80 \pm 5.69$ & $0.017^{*}$ \\
\hline $\mathrm{S}_{0} \mathrm{~N}_{270}$ & & & -9.70 & 6.50 & $-4.06 \pm 4.85$ & -15.50 & 6.40 & $-7.26 \pm 5.26$ \\
\hline
\end{tabular}

TMST: Turkish matrix sentences test, HA: Hearing aid, $\mathrm{S}_{0} \mathrm{~N}_{0}$ speech and noise from front $\left(0^{0}\right.$ azimuth), $\mathrm{S}_{0} \mathrm{~N}_{90}$ : speech from front and noise from right $\left(90^{\circ}\right.$ azimuth), $\mathrm{S}_{0} \mathrm{~N}_{270}:$ speech from front and noise from left $\left(270^{\circ}\right.$ azimuth), Min: Minimum, Max: Maximum, SD: Standard deviation 


\section{Discussion}

Speech tests are the primary tests used to diagnose hearing disorders and to evaluate hearing amplification process (20). Conventional speech recognition tests used in speech audiometry have limitations, dependent on the open response format, the practitioner, and the language. To resolve these limitations researchers developed matrix sentence tests that can be applied to many natural languages $(13,14)$. Matrix tests can be performed using different types of noise (21).

In the presented study, speech performances of hearing aid users were evaluated with two different types of noise (constant and fluctuating) by using the Turkish matrix sentence test (TMST). TMST scores of individuals with hearing aid were higher than the scores obtained without hearing aid in the free field in different azimuths $\left(\mathrm{S}_{0} \mathrm{~N}_{0}\right.$, $\mathrm{S}_{0} \mathrm{~N}_{90}$, and $\left.\mathrm{S}_{0} \mathrm{~N}_{270}\right)$ and different noises $(\mathrm{p}<0.05)$. This finding suggested that bilateral amplification is advantageous over

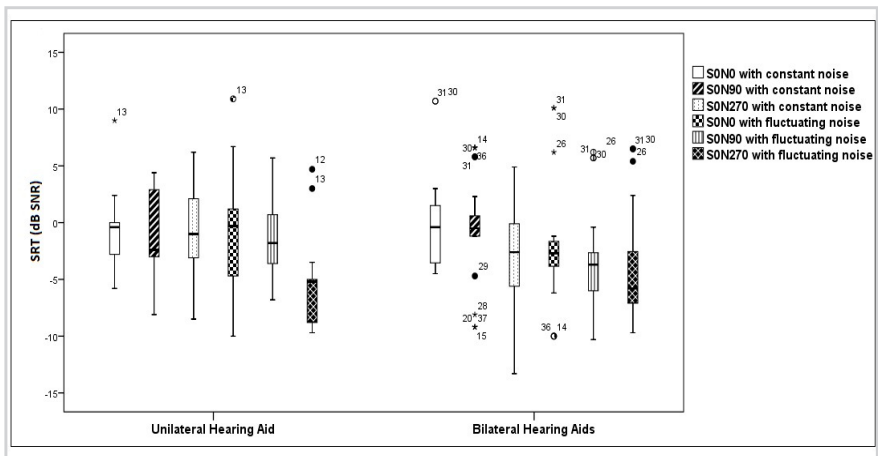

Figure 1. Turkish matrix sentence test results of bilateral and unilateral hearing aid users in different types of noise

SRT: Speech reception threshold, SNR: Signal-to-noise ratio

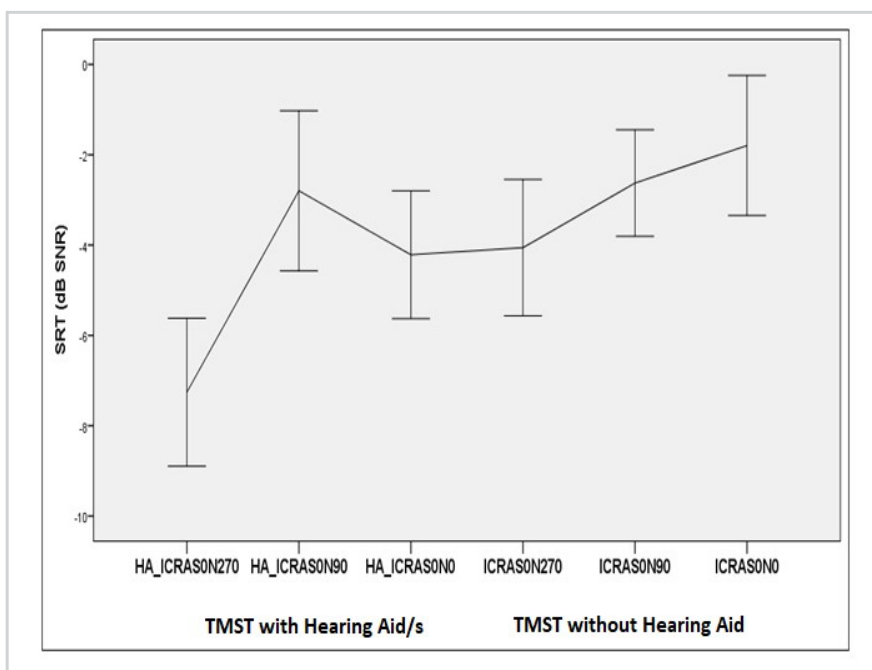

Figure 2. Turkish matrix sentence test results with/without hearing aid/s in fluctuating noise

TMST: Turkish matrix sentences test, SRT: Speech reception threshold, SNR: Signal-to-noise ratio unilateral amplification. Many studies in the literature indicate the benefits of bilateral amplification $(22,23)$.

Ahlstrom et al.(24) used HINT in their study and reported that the use of hearing aids improved the audibility of speech and led to an increase in speech perception. Having used the matrix sentence test in their study, Gallo and Castiglione (25) reported that speech recognition skills were better in individuals who had a hearing aid in one ear and a cochlear implant in the other compared to those who used cochlear implant alone, and that the use of contralateral hearing aids (especially in bilateral amplification) positively affected the level of speech intelligibility.

The type of speech material and the features of the noise are essential factors affecting speech intelligibility, regardless of the signal-to-noise ratio (SNR) (26). In the presented study, we obtained lower scores in fluctuating noise than in constant noise, and this finding is comparable to the results reported by Kollmeier et al. (13). Noise differences may have different effects on speech intelligibility. Although there were individual differences, it is indicated that the speech intelligibility of listeners with normal hearing is increased when fluctuating noise (such as ICRA noise) is used instead of constant noise $(2,8)$. There were individual differences in our study, as well, and we thought that these differences might be due to the educational levels and lack of attention of the individuals. These factors are the limitations of our study.

In other studies, it has been stated that the speech-recognition threshold in fluctuating noise was $10 \mathrm{~dB}$ lower than noise with headphones in matrix test $(8,27)$. The advantage of the fluctuating noise depends on the duration of low-level intervals found in the noise $(28,29)$. We found the highest TMST score with the hearing aid in our design (free field) for fluctuating noise (Figure 2). In our study, it was found that the most effective noise used in the TMST test was constant noise, and this finding was consistent with the work of Wagener et al. (30). The highest (worst) thresholds were measured when speech and noise sources were in the same phase $\left(\mathrm{S}_{0} \mathrm{~N}_{0}\right)$, and the lowest (best) thresholds were observed when speech and noise were in different phases $\left(\mathrm{S}_{0} \mathrm{~N}_{90}\right.$ or $\left.\mathrm{S}_{0} \mathrm{~N}_{270}\right)$. In our study, the most significant change (better level) in speech reception threshold (SRT) value for those with hearing aids was observed in $\mathrm{S}_{0} \mathrm{~N}_{90}$ and $\mathrm{S}_{0} \mathrm{~N}_{270}$ conditions regardless of the noise type (Figure 2 and Figure 3 ), and this finding is consistent with the study of Freyman et al. (31). When speech and noise sources are presented to the listeners separately, delayed reflections from each source may affect the interaural time and level differences associated with that source (31). SRT difference between $\mathrm{S}_{0} \mathrm{~N}_{0}$ and $\mathrm{S}_{0} \mathrm{~N}_{90}$ conditions shows the level of intelligibility $(32,33)$. If speech intelligibility in noise is spatially measured 


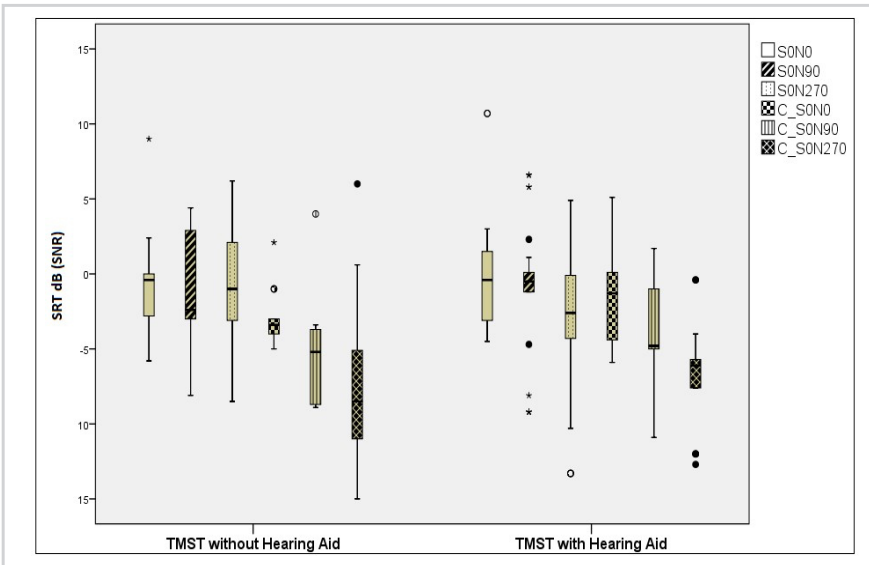

Figure 3. Turkish matrix sentence test results with/without hearing aid/s (HA) in constant noise

SRT: Speech reception threshold, SNR: Signal-to-noise ratio

with the binaural method, due to the azimuth difference, changes of more than $10 \mathrm{~dB}$ can be detected in people with normal hearing (34). In our study, different levels of speech recognition in two different noise types (between $\mathrm{S}_{0} \mathrm{~N}_{0}$ and $\mathrm{S}_{0} \mathrm{~N}_{90}$ and between $\mathrm{S}_{0} \mathrm{~N}_{0}$ and $\mathrm{S}_{0} \mathrm{~N}_{270}$ ) and lower level of SRT in the TMST with hearing aids suggested that using hearing aids positively contributes to spatial speech perception skills.

As a result, since fluctuating noise does not completely mask speech and speech-like sounds, it can be a useful type of noise that can be used in the evaluation and follow-up of the auditory rehabilitation process compared to constant noise.

\section{Conclusion}

TMST is a useful test for evaluating the speech recognition level of hearing aid users. That better matrix sentence test levels were found in bilateral hearing aid users under different noise and listening conditions compared to unilateral hearing aid users showed that the latter group could improve speech intelligibility in noise by using interaural difference cues with bilateral amplification. Because fluctuating noise resembles environmental sounds in daily life, it could provide useful information in assessing speech perception skills of hearingimpaired individuals. Using speech recognition levels in determining spatial perception provides convenience in the clinical examination of various types of hearing aid users.

Ethics Committee Approval: This study was approved by Ankara Yildırım Beyazıt University Ethics Committee (approval no: 55-14).

Informed Consent: Informed consent forms were signed by all participants.

Peer-review: Externally peer-reviewed.

\section{Authorship Contributions}

Conception: B.Ç., Supervision: S.T.Y., Data Collection and/ or Processing: B.Ç., Analysis and/or Interpretation: B.Ç., Literature Review: B.Ç., Writing: B.Ç., Critical Review: S.T.Y.

Conflict of Interest: No conflict of interest was declared by the authors.

Financial Disclosure: The authors declared that this study has received no financial support.

\section{Main Points}

- The Turkish matrix sentence test is a useful tool for assessing the speech recognition of individuals with hearing loss.

- The Turkish matrix test can be used to monitor the auditory rehabilitation process in individuals with hearing loss.

- Turkish matrix sentence test gives more reliable and more precise results in evaluating hearing aid performance under constant noise compared to other noise types.

- It is important to pay attention to the localization difference in device adaptation when evaluating the speech recognition skills of individuals with hearing loss with the Turkish matrix sentence test.

\section{References}

1. Harkins J, Tucker P. An internet survey of individuals with hearing loss regarding assistive listening devices. Trends Amplif 2007; 11: 91-100. [Crossref]

2. Bronkhorst AW. The cocktail party phenomenon: A review of research on speech intelligibility in multiple-talker conditions. Atten Percept Psychophys 2000; 86: 117-28. [Crossref]

3. Holmes H. The effects of background sound on communication: speech intelligibility and reading: University of Southampton; Doctoral Thesis, 2015. [Crossref]

4. Gürses E, Türkyılmaz MD, Sennaroğlu G. Evaluation of auditory temporal processing in patients fitted with bone-anchored hearing aids. Eur Arch Otorhinolaryngol 2020; 277: 351-9. [Crossref]

5. Zeng FG, Nie K, Stickney GS, Kong YY, Vongphoe M, Bhargave $A$, et al. Speech recognition with amplitude and frequency modulations. Proc Natl Acad Sci U S A 2005; 102: 2293-8. [Crossref]

6. Dreschler WA, Verschuure H, Ludvigsen C, Westermann SJA. ICRA noises: artificial noise signals with speech-like spectral and temporal properties for hearing instrument assessment: Ruidos ICRA: Señates de ruido artificial con espectro similar al habla y propiedades temporales para pruebas de instrumentos auditivos. 2001; 40: 148-57. [Crossref]

7. Hey M, Hocke T, Hedderich J, Müller-Deile J. Investigation of a matrix sentence test in noise: reproducibility and discrimination function in cochlear implant patients. Int J Audiol. 2014; 53: 895902. [Crossref] 
8. Wagener KC, Brand TJ. Sentence intelligibility in noise for listeners with normal hearing and hearing impairment: Influence of measurement procedure and masking parameters La inteligibilidad de frases en silencio para sujetos con audición normal y con hipoacusia: la influencia del procedimiento de medición y de los parámetros de enmascaramiento. 2005; 44: 144-56. [Crossref]

9. Nilsson M, Soli SD, Sullivan JA. Development of the Hearing in Noise Test for the measurement of speech reception thresholds in quiet and in noise. J Acoust Soc Am 1994; 95: 1085-99. [Crossref]

10. Wilson RH, Carnell CS, Cleghorn AL. The Words-in-Noise (WIN) test with multitalker babble and speech-spectrum noise maskers. J Am Acad Audiol 2007; 18: 522-9. [Crossref]

11. Ozimek E, Warzybok A, Kutzner DJIjoa. Polish sentence matrix test for speech intelligibility measurement in noise. Int J Audiol 2010; 49: 444-54. [Crossref]

12. Jansen S, Luts H, Wagener KC, Kollmeier B, Del Rio M, Dauman $\mathrm{R}$, et al. Comparison of three types of French speech-in-noise tests: A multi-center study. Int J Audiol 2012; 51: 164-73. [Crossref]

13. Kollmeier B, Warzybok A, Hochmuth S, Zokoll MA, Uslar V, Brand T, et al. The multilingual matrix test: Principles, applications, and comparison across languages: A review. Int J Audiol 2015; 54(Supp12): 3-16. [Crossref]

14. Zokoll MA, Fidan D, Türkyılmaz D, Hochmuth S, Ergenç İ, Sennaroğlu G, et al. Development and evaluation of the Turkish matrix sentence test. Int J Audiol 2015; 54(Suppl2): 51-61. [Crossref]

15. Wagener K. Factors influencing sentence intelligibility in noise: BIS Verlag; 2004.

16. Durankaya SM, Serbetçioglu B, Dalkiliç G, Gürkan S, Kirkim G. Development of a Turkish monosyllabic word recognition test for adults. J Int Adv Otol 2014; 10: 172-180. [Crossref]

17. International Organization for Standardization. Acoustics - Audiometric test methods. Basic pure tone air and bone conduction threshold audiometry 1989; (ISO 8253 Pt 1). Geneva: ISO. [Crossref]Brand T, Kollmeier BJTJotASoA. Efficient adaptive procedures for threshold and concurrent slope estimates for psychophysics and speech intelligibility tests. J Acoust Soc Am 2002; 111: 2801-10. [Crossref]

18. ICRA. International collegium of reabilitative audiology. Noise Signals. 1997.

19. Cesur S, Derinsu U. Temporal processing and speech perception performance in postlingual adult users of cochlear implants. J Am Acad Audiol 2020; 31: 129-36. [Crossref]

20. Akeroyd MA, Arlinger S, Bentler RA, Boothroyd A, Dillier N, Dreschler WA, et al. International Collegium of Rehabilitative Audiology (ICRA) recommendations for the construction of multilingual speech tests: ICRA Working Group on
Multilingual Speech Tests. International journal of audiology. 2015;54(Supp12):17-22. [Crossref]

21. Hornsby BW, Ricketts TA. Effects of noise source configuration on directional benefit using symmetric and asymmetric directional hearing aid fittings. Ear Hear 2007; 28: 177-86. [Crossref]

22. Drennan WR, Gatehouse S, Howell P, Van Tasell D, Lund S. Localization and speech-identification ability of hearing-impaired listeners using phase-preserving amplification. Ear Hear 2005; 26: 461-72. [Crossref]

23. Ahlstrom JB, Horwitz AR, Dubno JR. Spatial benefit of bilateral hearing aids. Ear Hear 2009; 30: 203-208. [Crossref]

24. Gallo S, Castiglione AJH. The signal-to-noise ratio assessment in cochlear implanted patients through the Italian Matrix Sentence test (Oldenburg test). Hear Balance Commun 2019; 17: 145-8. [Crossref]

25. Soli SD, Wong LL. Assessment of speech intelligibility in noise with the Hearing in Noise Test. Int J Audiol 2008; 47: 356-61. [Crossref]

26. Hochmuth S, Kollmeier B, Brand T, Jürgens TJ. Influence of noise type on speech reception thresholds across four languages measured with matrix sentence tests. Int J Audiol 2015; 54(Suppl2): 62-70. [Crossref]

27. Dubno JR, Horwitz AR, Ahlstrom JB. Benefit of modulated maskers for speech recognition by younger and older adults with normal hearing. J Acoust Soc Am 2002; 111: 2897-907. [Crossref]

28. Nelson PB, Jin SH, Carney AE, Nelson DA. Understanding speech in modulated interference: Cochlear implant users and normalhearing listeners. J Acoust Soc Am 2003; 113: 961-8. [Crossref]

29. Wagener KC, Brand T, Kollmeier BJIJoA. The role of silent intervals for sentence intelligibility in fluctuating noise in hearingimpaired listeners: El papel de los intervalos de silencio para la inteligibilidad de frases en medio de ruido fluctuante en sujetos hipoacùsicos. Int J Audiol 2006; 45: 26-33. [Crossref]

30. Freyman RL, Helfer KS, McCall DD, Clifton RK. The role of perceived spatial separation in the unmasking of speech. J Acoust Soc Am 1999; 106: 3578-88. [Crossref]

31. Peissig J, Kollmeier B. Directivity of binaural noise reduction in spatial multiple noise-source arrangements for normal and impaired listeners.J Acoust Soc Am 1997; 101: 1660-70. [Crossref]

32. Platte HJ, Vom Hövel H. Zur Deutung der Ergebnisse von Sprachverständlichkeitsmessungen mit Störschall im Freifeld. Acta Acustica United with Acustica (article in German). 1980; 45: 139-50. [Crossref]

33. Bronkhorst A, Plomp RJTJotASoA. Effect of multiple speechlike maskers on binaural speech recognition in normal and impaired hearing. J Acoust Soc Am 1992; 92: 3132-9. [Crossref] 